\title{
RESEARCH PAPER \\ PREVALENCE OF HEARING LOSS IN PATIENTS WITH ACUTE OTITIS MEDIA
}

\author{
P. Awuah, I. M. Duah and G. K. Amedofu \\ Department of Eye, Ear, Nose and Throat, School of Medical Sciences, College of Health Science \\ KNUST, Kumasi
}

\begin{abstract}
:
The study was a prospective, cross-sectional type conducted at the Ear, Nose and Throat Department of Komfo Anokye Teaching Hospital (KATH) over a six month period from $1^{\text {st }}$ August 2005 to $31^{\text {st }}$ January 2006. Fifty one patients involving 69 ears (few with bilateral and majority with unilateral hearing loss) were interviewed followed by otoscopic ear examination, pure tone audiometry using AC 30 audiometer and tympanometric test. The hearing loss of participants was thus determined before and after treatment to establish the change in hearing over the period. The results showed that hearing loss occurs in majority of sufferers of acute otitis media. The prevalence of acute otitis media (AOM) is low in adults, but it is quite high in children (91.3\%) of reported cases.
\end{abstract}

Keywords: Acute otitis media, hearing loss, tympanometry, Pure-tone Audiometry

\section{INTRODUCTION}

Middle ear infection is eminently amenable to treatment, and early effective management will prevent progression to Chronic Suppurative Otitis Media and subsequent Cholesteatoma and Sensorineural hearing loss. Whilst Chronic Middle Ear disease is no longer common in the developed countries, it is still a major cause of morbidity in poorer countries where it is the most prevalent ear disease (Wilson, 1988). Problems exhibited in speech/language production, perception and academic achievement are related to degree of hearing loss and age of onset (Northern and Downs, 1974). The majority of children with Otitis Media have clinically normal hearing (Lewis, 1976).The mild hearing loss due to Serous Otitis Media, and its complications, in the early years of life has long been overlooked as a major cause of speech and language deficiencies. Estimates have been made that between $76 \%$ and $95 \%$ of all children have at least one episode of otitis media by the age of 6 years (Howie et al., 1975). Although onethird of children with isolated episodes of middle ear effusion recover spontaneously, approximately $20 \%$ of children seen by primary health care physicians have recurrent Otitis Media (Brooks, 1976). It is increasingly apparent that recurrent otitis media with hearing loss may contribute to educational problems 
(Northern and Downs, 1978). Some of these children are inadvertently labeled as Learning Disabled' or show behavioral problems as a result of their hearing problem.

Ross and Giolas (1978) suggested that a child with a loss of $15 \mathrm{~dB}$ HL or more in the speech frequencies in the better ear is at risk of hearing loss. Young children are more prone to otitis media (Wilson, 1990). Indeed, Greater Boston Study found that more than $60 \%$ of children had at least one episode of acute otitis media by age $1,80 \%$ had one episode by 3 years of age and more than $40 \%$ at least 3 episodes. In the United Kingdom, 3\% of children less than 3 years visit the general practitioner with acute otitis media each year, $97 \%$ of whom (3\%) will receive antimicrobial treatment (O'Neil, 2000). In the United States of America, acute otitis media is the most common reason for out patient antimicrobial treatment (Tele and Klein, 1989). Reports from review of school and community-based studies gave prevalence between 0.4 and 6.1 percent in low and middle income countries (Berman, 1995). Wilson (1988) states that $5.6 \%$ of school-age Burmese children had hearing impairment sufficient to interfere with education and that $80 \%$ of these cases were due to otitis media. Data is available on the Prevalence of Otitis media in Nigeria (Miller et al., 1983). A thorough review of the literature indicate that so far no study involving the use of Pure-tone Audiometry, Tympanometry and a detailed stastistical analysis has been conducted in Ghana on acute otitis media. There is therefore the need to conduct such an investigation; hence, the impetus for this study.

\section{METHODOLOGY}

The study was done at the outpatient unit of the Ear, Nose and Throat department of the Komfo Anokye Teaching Hospital (KATH) Kumasi, Ghana. The facility has a large catchment area of Central and Northern Sectors of Ghana and sees about 100 patients daily. The study was a prospective, descriptive cross-sectional type conducted from the month of August 2005 to January 2006 (6 months). Out of the ten thou- sand one hundred and sixty one patients (10,161 who attended the ENT clinic for various ENT diseases, 268 with ear infections were screened and 188 who received the diagnosis of AOM were eligible for the study and 80 not eligible and therefore excluded from the study. These patients were seen and recruited into the study by specialists and resident doctors of the ENT department. Each participant was interviewed, followed by Otoscopic ear examination, pure tone audiometry using AC 30 audiometer and tympanometry test. Case report forms were then used per patient for documenting patient data. Participating patients were taken through same process again after two weeks of medical treatment. The treatment modality given was a broad spectrum antibiotics such as penincillin.

Data was entered into Epi Info version 3.3 and screened from abnormal figures and values. The data was then transferred to state intercool version 8 and Excel for analysis. Basic descriptive analyses of baseline characteristics were provided; mean, median as measure of central tendency and range for measure of dispersion. Ninety five confidence interval (CI) baseline characteristics were provided. Multivariate analysis was employed using chi-square and student t-test as appropriate.

\section{RESULTS}

During the six months study period, the ENT clinic attended to a total of 10,161 patients suffering from various ENT diseases. Two hundred and sixty eight patients with ear infections were screened and 188 received the diagnosis of AOM and hence eligible for the study and 80 not eligible. In all, 63 ears (with unilateral and bilateral hearing losses) out of 69 ears diagnosed with acute otitis media developed hearing loss, giving the prevalence of hearing loss as $91.3 \%$; 37 out of the 51 patients $(72.55 \%)$ admitted to having $\mathrm{H} / \mathrm{L}$ at the time of reporting at the ENT Clinic. The prevalence of AOM was thus obtained as $1.85 \%$. One hundred and seventy patients /guardians gave consent and were included in the study while 18 patients were not 
included for lack of consent. The one hundred and seventy who consented to join the study were taken through the initial phase of the clinical and audiometric examination and were given treatment on out-patient basis.

Out of these 170 patients, only 51 patients returned for review to undertake the second phase of the clinical and audiometric examination. Robinson et al. (1988) in the screening study of children encountered a similar situation where only about one-half of the children who needed to be re-screened returned for testing. Complete data was thus, obtained for only 51 patients which was then entered for analysis. Table I depicts symptoms of patients before and after treatment. Of the 51 patients for analysis, there were 24 males, $(47.06 \%)$ and 27 females $(52.94 \%)$ giving male to female ration of $1: 1.1$. Forty-three patients had no earlier history of acute otitis media representing $84.31 \%$ of those analysed. Their ages ranged between 9 and 64 years giving the mean age 33.6 years (STD 15.27, STD. Err. 2.1384) (C1=29.3 - 37.9).

Table 2 shows the various signs of the ear before and after treatment. It can be observed that the values for the reddening of the eardrum and the row for the loss of light reflex are the same. This is because the reddened tympanic membrane in that condition would lose its shine and ability to reflect light. We noted that thirtyseven of the patients reported within the first week of onset of their ear condition representing $72.55 \%$ while 14 patients $(27.45 \%)$ reported within the second week of their illness. Again, out the of 51 patients, 19 patients had only their left ears involved (37\%), 14 patients (27.4\%) had their right ears involved and 18 patients $(35 \%)$ had both their left and right ears involved at the same time. In this way 69 ears with unilateral and bilateral hearing loss of 51 patients were analysed in the study. Pure-tone audiometric analysis gave a mean change in hearing in the 69 ears tested after medical intervention as 13.75dB HL (Std Dev. 12.3).

The maximum change in hearing was $50 \mathrm{~dB}$ HL in one patient while the minimum of $5 \mathrm{~dB} \mathrm{HL}$ was recorded in two patients (a negative value represents a worsening in hearing after treatment). One patient had a change in hearing of $3 \mathrm{~dB}$ HL and 6 patients had no change in their hearing $(8.7 \%)$. We see in Table 3 the number of episodes per patient. It can be observed that the high frequency of episodes occurred within the first period. We see in Table 4 the tympanometric measurements of the ears involved. We observed that 41 out of the 69 ears registered type A tympanometric tracing representing $59.4 \%$ of the total before treatment while $24(34.78 \%)$ ears registered a type B tracing. There was only $1(1.45 \%)$ type $\mathrm{C}$ tracing. Three ears did not have tympanometric testing done on them as a result of equipment failure. After treatment however some improvements in the tympanometric measurements were noted.

\section{DISCUSSION}

Prevalence estimates for hearing impairment vary depending on age and criteria used to define the various causes of the conditions. At any given time, about $5-7 \%$ of children ages between 5 and 8 have $25 \mathrm{~dB}$ hearing loss (Cross, 1985). Impaired hearing function begins at an average hearing level of $25 \mathrm{~dB}$ for the select frequencies and is complete at $92 \mathrm{~dB}$ HL. It is estimated that the overall prevalence figures for children with hearing loss, defined as $15 \mathrm{~dB} \mathrm{HL}$ or worse, for frequencies of $500 \mathrm{~Hz}$ to $2000 \mathrm{~Hz}$, is $10 \%$ in the birth to 11 year-old group (Northern and Downs, 1978). The prevalence of acute otitis media in our study turned out to be $1.85 \%$. Similar findings were obtained in other developing countries in a review by Berman (1995) where a school and community based studies gave prevalence of between 0.4 and 6.1 percent in low and middle income countries (Berma, 1995).

The prevalence rate across all ages for otitis media was $5.6 \%$ and for otitis media with effusion was $2.3 \%$. Similarly, a study by Miller et al. (1983) in Nigerians revealed a point prevalence of otitis media in children $(<15$ years of age) to be $21.7 \%$ compared to $4 \%$ in adults 
Awuah et al.

Table 1: Symptoms with their percentages before and after treatment

\begin{tabular}{lcccc}
\hline Symptoms & $\begin{array}{l}\text { Before treatment } \\
\text { presenting with: }\end{array}$ & No. of people & $\begin{array}{l}\text { After treatment } \\
\text { presenting with: }\end{array}$ & No. of people \\
& No. & $(\boldsymbol{\%})$ & No. & $(\boldsymbol{\%})$ \\
\hline Otalgia & 42 & 82.35 & 8 & 15.69 \\
Hearing Loss & 37 & 72.55 & 7 & 13.69 \\
Tinnitus & 35 & 68.63 & 8 & 1.69 \\
Autophony & 35 & 68.63 & 6 & 11.76 \\
Dizziness/Vertigo & 2 & 03.92 & 0 & 0.0 \\
Headache & 24 & 47.06 & 7 & 13.73 \\
Fever & 11 & 21.57 & 2 & 03.92 \\
Chills & 2 & 0.92 & 1 & 1.96 \\
Recurrent Catarrh/ & 37 & 72.55 & - & - \\
Cough & & & & \\
Recently treat for & 2 & 03.92 & & - \\
malaria & & & & \\
& & & & \\
\hline
\end{tabular}

Table 2: Patients showing various signs

\begin{tabular}{lcccc}
\hline Signs & No. before treatment & $\begin{array}{c}\text { Percentage } \\
(\boldsymbol{\%})\end{array}$ & No. after treatment & $\begin{array}{c}\text { Percentage } \\
(\%)\end{array}$ \\
\hline $\begin{array}{l}\text { Reddening of } \\
\text { ear drum }\end{array}$ & 51 & 100 & 28 & 55 \\
$\begin{array}{l}\text { Bulging of ear- } \\
\text { drum }\end{array}$ & 7 & 14 & 0 & 0 \\
$\begin{array}{l}\text { Retraction of } \\
\text { eardrum }\end{array}$ & 1 & 2.0 & 0 & 0 \\
$\begin{array}{l}\text { Loss of light } \\
\text { reflex }\end{array}$ & 51 & 100 & 28 & 55 \\
\hline
\end{tabular}

(> 15 years of age). The above studies show high prevalence rates for children and low rates for adults confirming children's proneness to otitis media. Our study recorded a low prevalence rate of $1.85 \%$ due to our exclusion of children under seven years of age from the study for technical difficulties involved in assessing hearing of young children. Similar limitations confronted by Babagana et al.(1999) in Nigeria urged them to exclude children aged under six years. The current study revealed that 63 out of the 69 ears after audiometric ass- 
Table 3: Number of episodes per patient

\begin{tabular}{lcc}
\hline No. of Episodes & $\begin{array}{c}\text { No. of patients } \\
\text { (Frequency) }\end{array}$ & $\begin{array}{c}\text { Percentage } \\
(\mathbf{\%})\end{array}$ \\
\hline First episode & 43 & 84 \\
Second episode & 4 & 8 \\
Third episode & 3 & 6 \\
Fourth episode & 0 & 0 \\
Fifth episode & 1 & 2.0 \\
Total & $\mathbf{5 1}$ & $\mathbf{1 0 0}$ \\
\hline
\end{tabular}

Table 4: Tympanometric measurements of the involved ears and their percentages before and after treatment

\begin{tabular}{lcccc}
\hline Tympanometry & $\begin{array}{l}\text { Before treatment } \\
\text { No. of ears }\end{array}$ & $\begin{array}{c}\text { Percentage } \\
(\mathbf{\%})\end{array}$ & $\begin{array}{c}\text { After treatment } \\
\text { No. of ears }\end{array}$ & $\begin{array}{c}\text { Percentage } \\
(\mathbf{\%})\end{array}$ \\
\hline Type A & 41 & 60 & 45 & 66 \\
Type B & 24 & 35 & 18 & 26 \\
Type C & 1 & 2.0 & 3 & 5 \\
Not done & 3 & 5 & 3 & 5 \\
Total & $\mathbf{6 9}$ & $\mathbf{1 0 0}$ & $\mathbf{6 9}$ & $\mathbf{1 0 0}$ \\
\hline
\end{tabular}

essment showed hearing loss as a result of acute otitis media giving the prevalence of hearing loss of $91.3 \%$. This is not very different from what Wilson (1988) found in Burmese children. Indeed, 37 (72.55\%) patients out of 51 patients recruited into the study admitted to having hearing loss. Thus, although only a mild change in hearing is brought about by an episode of an acute otitis media, significant proportion of patients with the condition suffer some hearing loss as indicated by this study.

The mean change in hearing in our study of the the 69 ears tested was $13.75 \mathrm{~dB}$ HL. This was probably as a result of the fact that most of the patients (43 out of 51 i.e. 84\%) analysed in the study claimed that the acute otitis media was their first time episode. Furthermore as many as 37 patients $(72.55 \%)$ reported within one week of the onset of their symptoms. Six ears representing $8.7 \%$ had no change in their hearing whilst 3 ears $(4.35 \%)$ worsened in their hearing. The observation made by Eagles et al. (1967) that, the majority of patients with otitis media have clinically normal hearing is in perfect agreement with our calculated value. That 
not withstanding it is our belief that the early quest for medical intervention by patients in the study and the fact that the otitis media was their first episode explain why the mean change in hearing was $13.75 \mathrm{~dB}$ HL. Cognizant of the fact that problems exhibited in speech/language production, perception and academic achievement are related to degree of hearing loss and age of onset (Ross and Giolas, 1978). It is worth noting that, even the children with the mildest loses show academic handicap (Howie et al., 1976). Indeed Lewis (1976), in his study of Australian aboriginal children concluded that the mere presence of otitis media can be taken as evidence that a handicapping hearing condition exists. With little time to recuperate loss of hearing, it may not be difficult to understand why children with repeated episodes of acute otitis media are handicapped in education and acquisition of speech and language (Brandes, 1981).

In our study, whilst 24 ears $(34.78 \%)$ generated type B tympanograms prior to treatment, only 18 ears $(26 \%)$ generated type B tympanograms after treatment. This appears to confirm the observation made by Robinson et al. (1988) that, the probability of a type B tympanogram changing over time is lower than for any of the other types of tympanograms. However, in his study of five hundred and forty four 3 year to 11 year-old Nigerian children for serous otitis media, Okeowo (1978) using immitance testing obtained type B tympanograms in $4.9 \%$ of children. Thus, it would appear that AOM produces more Type B tympanograms than serous otitis media. The current study recorded a slight improvement in the number of ears with type A tympanograms from initial 41 ears $(59.4 \%)$ to 45 ears $(65.22 \%)$.

In addition, our study showed otalgia as the most frequent symptom in acute otitis media involving 42 ears $(82.35 \%)$ of the study population, followed by hearing loss, tinnitus and autophony. There was however dramatic improvement in these symptoms after two weeks of medical treatment. The treatment modality given was a broad spectrum antibiotics such as penincillins (amoxacillin-clavulanic acid combination). We did not address the question of causative agents responsible for the aetiology of AOM in this paper because we do not have the facility to do tympanocentesis to take specimen for microbiological analysis in our part of the world. The recovery from the signs at initial presentation however lagged behind the recovery of symptoms since about half the patients still had some reddening of their eardrums with loss of light reflex. Although this observation corroborates the notion that recovery of signs takes a little longer time to complete, it could also signify the persistence of the otitis media (Elton and Cornell, 1978).

\section{CONCLUSION}

It has become obvious from the current study that although the hearing loss in an episode of acute otitis media is mild, it occurs consistently in majority of the sufferers of the AOM. The prevalence of AOM in the adult is low; it is however quite high in the children in whom repeated episodes of the condition is also common. Since as high as $91.3 \%$ of ears that develop AOM sustain significant amount of hearing loss, repeated episode of the condition with little time for the improvement of the Hearing acuity may perpetuate the degree of Hearing loss in such children. Acute otitis is highly amenable to medical treatment with very good rate of symptoms and signs resolution if medical care is sought early and promptly enough.

\section{REFERENCES}

Berman, S. (1995). Otitis in developing countries. Pediatrics, 96: 126-3.

Brandes, P. J. and Ehinger, D. M. (1981). The effects of early middle ear pathology on auditory perception and academic achievement. $J$. Speech Hear. Disord, 46: 301-307.

Brooks, D. (1976). School screening for middle ear with effusion. Ann. Otol. Rhinol. Laryngology, (Suppl. 25) 85: 225-228. 
Cross, A. W. (1985). Health Screening in Schools. Pediatrics, 107: 487-494.

Eagles. E. L., Wilshink, S. M. and Doerfler, L. G. (1967). Hearing Sensitivity and ear disease in children. Laryngoscope, (Suppl.) 1 274.

Elton, P. and Cornell, J. (1978). Study of Otitis Media and Malaria among attenders at Under 5 Clinic. J. Tropical Medicine and Hygiene, 81: $110-112$.

Howie, V. M., Ploussard, J. H. and Sloyer, J. L. (1976). Natural history of Otitis Media. Ann. Otol. Rhinol Laryngol, Suppl. 85: 18-21.

Howie, V. M., Ploussard, J. H. and Sloyer, J. L. (1975). The 'Otitis Prone' condition. American Journal of Diseases of Children, 129: 676-678.

Lewis, N. (1976). Otitis Media and linguistic incompetence. Arch. Otolaryngol., 102: 387390.

Lundborg, T. (1987): Clinical Rehabilitation of the Deaf. Advances in Oto-Rhino Laryngology, 37: 158-161

Miller, S. A, Omene, J. A. and et al. (1983). A Point Prevalence of Otitis Media in a Nigerian village. Int. Journal of Pediatric Otolaryngology, 5: 19-29.

Northern, J. L. and Downs, M. P. (1978). Hearing in Children. Ed. 2, Williams and
Wilkins, Baltimore 1978.

Northern, J. L. and Downs, M. P. (1974). Identification audiometry, in Hearing in Children. Williams and Wilkins, Baltimore. Pp.93-133.

Okeowo, P. A. (1978). Observations of Nonsuppurative Middle Ear Problems in Nigerian children. Tropical Pediatrics and Environmental Child Health. 24: 4-6

Ornell, P. (2000). Acute Otitis Media. Clinical Evidence. 3: 156-62

Robinson, D. O., Allen, D. V. and Root, L. P. (1988). Infant Tympanometry. J. Speech and Hearing Disorders, 53: 341-346

Ross, M. and Giolas, T. G. (1978). Introduction. In: Ross, M. and Giolas. T. G. Eds. Auditory Management of Hearing Impaired Children. University Park Press, Baltimore. 1 $-13$

Teele, D. W. and Klein, J. O. (1989). Epidemology of otits media during the first seven years of life in children in greater Boston. Journal of infection. 4: 20-27

Wilson, J. (1988). Deafness in Developing countries - Approaches to a global Programm of prevention. Scandinavian Audiology, Suppl. 28: 37-58

Wilson, J. (1990). Hearing-impairment In Developing Countries. Journal of Otolaryngology, 19: 368-371. 